\title{
Digital health technology for use in patients with serious mental illness: a systematic review of the literature
}

\author{
Sonal Batra' \\ Ross A Baker² \\ Tao Wang ${ }^{3}$ \\ Felicia Forma ${ }^{4}$ \\ Faith DiBiasi ${ }^{3}$ \\ Timothy Peters-Strickland ${ }^{5}$ \\ 'Department of Psychiatry, Rutgers \\ Robert Wood Johnson Medical School, \\ Piscataway, ${ }^{2}$ Global Medical Affairs, \\ Otsuka Pharmaceutical Development \\ and Commercialization Inc., \\ Princeton, NJ, ${ }^{3}$ Medical Affairs, Otsuka \\ Pharmaceutical Development and \\ Commercialization Inc., Rockville, MD, \\ ${ }^{4} \mathrm{Health}$ Economics and Outcomes \\ Management, ${ }^{5} \mathrm{Global}$ Clinical \\ Development, Otsuka Pharmaceutical \\ Development and Commercialization \\ Inc., Princeton, NJ, USA
}

Correspondence: Timothy Peters-Strickland

Global Clinical Development, Otsuka

Pharmaceutical Development and

Commercialization Inc., 508 Carnegie

Center Boulevard, Princeton,

NJ 08540, USA

Tel + I 6092496559

Fax +l 6092490559

Email tim.peters-strickland@otsuka-us.com
This article was published in the following Dove Press journal:

Medical Devices: Evidence and Research

4 October 2017

Number of times this article has been viewed

Background: As the capabilities and reach of technology have expanded, there is an accompanying proliferation of digital technologies developed for use in the care of patients with mental illness. The objective of this review was to systematically search published literature to identify currently available health technologies and their intended uses for patients with serious mental illness.

Materials and methods: The Medline, Embase, and BIOSIS Previews electronic databases were searched to identify peer-reviewed English language articles that reported the use of digital, mobile, and other advanced technology in patients with schizophrenia/schizoaffective disorder, bipolar disorder, and major depressive disorder. Eligible studies were systematically reviewed based on Preferred Reporting Items for Systematic Reviews and Meta-Analyses (PRISMA) guidelines.

Results: Eighteen studies that met the inclusion criteria were identified. Digital health technologies (DHTs) assessed in the selected studies included mobile applications (apps), digital medicine, digital personal health records, and an electronic pill container. Smartphone apps accounted for the largest share of DHTs. The intended uses of DHTs could be broadly classified as monitoring to gain a better understanding of illness, clinical assessment, and intervention. Overall, studies indicated high usability/feasibility and efficacy/effectiveness, with several reporting validity against established clinical scales. Users were generally engaged with the DHT, and mobile assessments were deemed helpful in monitoring disease symptoms.

Conclusion: Rapidly proliferating digital technologies seem to be feasible for short-term use in patients with serious mental illness; nevertheless, long-term effectiveness data from naturalistic studies will help demonstrate their usefulness and facilitate their adoption and integration into the mental health-care system.

Keywords: serious mental illness, health technology, mHealth, smartphone applications, digital medicine

\section{Introduction}

The global burden of mental illness is substantial. ${ }^{1}$ Serious mental illnesses (SMIs), such as bipolar disorder, schizophrenia, and major depressive disorder (MDD), are chronic conditions associated with significant disability, and often require continuous long-term treatment and care. In addition to the mental health-care system being overburdened, access, cost, and stigma are among several reported barriers to obtaining adequate mental health care. ${ }^{2-5}$ Emerging digital health technologies (DHTs) have provided a means to potentially overcome some of these obstacles and improve care. 
Digital technology has rapidly pervaded and transformed the daily lives of people. According to the Pew Research Center, $72 \%$ of the US population owned a mobile phone in $2015 .{ }^{6}$ In the same year, a report by the IMS Institute for Healthcare Informatics noted that 165,000 mobile health (mHealth) applications (apps) were available, two-thirds of which were focused on general wellness. ${ }^{7}$ There are fewer apps for mental health, but the numbers are growing. ${ }^{8}$ Developing DHTs that can be used by people with SMI can be particularly challenging because of illness-related factors, such as cognitive impairments, ${ }^{9}$ and thus requires specific design considerations. ${ }^{10,11}$ Nevertheless, results of several surveys indicate that patients with SMI are receptive to the use of technology. ${ }^{12-15}$ There are several examples of DHTs that have been developed for and used in psychiatry, ranging from computerized cognitive behavior therapy $(\mathrm{CBT})^{16}$ to symptom-monitoring apps ${ }^{17}$ to ingestible sensors. ${ }^{18}$

The potential advantages of technology in enhancing mental health care have been recognized and appreciated in several recent reviews. ${ }^{19-21}$ DHTs have created opportunities to develop a better understanding of MI and potentially improve the outcomes for patients with chronic mental health conditions in a variety of ways. Real-time longitudinal patient data can guide diagnosis and treatment decisions or facilitate timely interventions before a crisis develops. Remote on-demand provision of therapy allows for more consistent and accessible treatment. Objective measures of medication adherence allow for better-informed treatment decisions.

Previous reviews have focused on specific types of technology in specific populations. For example, Donker et al systematically reviewed studies of mental health apps for mobile devices, noting that there was insufficient scientific evidence to support their efficacy. ${ }^{22}$ The usability of mental health apps was perceived to be moderate-high, but evidence for their sustained use was not considered adequate, because most studies were of a short duration. Huguet et al reviewed available CBT and behavioral activation apps for depression, and concluded that there was not enough evidence available to support their use. ${ }^{23}$ Firth and Torous reviewed smartphone apps for schizophrenia. Although based on a small number of studies, the preliminary results indicated high rates of retention and adherence. ${ }^{24}$ While demonstrating the usability of DHTs, these reviews have emphasized the urgent need for data demonstrating efficacy. As noted earlier, these reviews have been limited in the type of technology or the disease state being evaluated. Moreover, studies on the use of advanced technology, such as wearable sensors, have not been addressed in previous reviews. HT is evolving at a rapid pace; therefore, to guide other developers of DHTs and to facilitate the adoption of various DHTs in clinical practice, it is important to review up-to-date available data on the usability and effectiveness of novel DHTs. The purpose of this systematic review is to identify currently available DHTs, encompassing mobile apps, eHealth, and other advanced technologies, and their intended use in patients with SMI, including schizophrenia, MDD, and bipolar disorders.

\section{Materials and methods}

A qualitative literature review was conducted based on the guidelines outlined by the Preferred Reporting Items for Systematic Reviews and Meta-Analyses (PRISMA) statement. ${ }^{25}$

\section{Literature search}

A search of the electronic databases Medline, Embase, and BIOSIS Previews was conducted to identify peer-reviewed English language articles published within 10 years of the search date of November 8, 2016. Because technology is evolving at a rapid pace, to avoid discussion of any technology that is now potentially obsolete, we limited our search to the previous 10 years. The search terms were designed to capture specific types of DHT intended for use in patients with SMI: ("digital medicine" OR "digital health" OR ehealth OR mhealth OR "mobile health" OR "mobile app*" OR "ingestible *sensor*" OR wearable OR "wireless system" OR "electronic adherence") AND (schizophrenia OR psychosis OR MDD OR depressi* OR bipolar) NOT (review OR meta-analysis OR diabetes OR hypertension OR cancer OR obesity OR prevention OR alcohol OR dementia OR Alzheimer* OR protocol OR stroke OR editor* OR Parkinson* OR cardi* OR "traumatic brain injury" OR "multiple sclerosis" OR "stress management" OR lupus OR HIV OR COPD OR adolescent OR PTSD OR "mobile health unit*” OR "conference abstract” OR note OR letter OR chapter OR "meeting poster" OR patent OR "short survey" OR "case report" OR "conference paper" OR "meeting abstract" OR news). To meet the criteria for inclusion, an article had to be a primary report of a prospective study involving $\geq 20$ participants, include patients with a diagnosis of SMI, defined here as bipolar disorder, schizophrenia, or MDD, and incorporate an intervention or assessment using digital, mobile, or other advanced technology.

\section{Article selection process}

Titles and abstracts of articles retrieved from the search were screened for eligibility by all authors. All authors also participated in full-text review, with each selected article being 
reviewed by two authors to identify those meeting the predefined criteria for inclusion. Review articles and commentaries were excluded. Randomized and nonrandomized studies and studies with and without control groups were included. Included articles reported technologies that required the participants to use and interact with the technology. Passive technology, such as videoconferencing, was excluded.

\section{Results}

\section{Article selection}

The search retrieved 133 records. After abstracts had been screened for eligibility, 82 were excluded. A full-text review of the remaining 51 potentially eligible articles was conducted. A total of 18 articles were included in the analysis. The most common reason for exclusion was that the article reported on a study conducted in a non-SMI study population (Figure 1).

Information on study design, patient population, and types of DHTs and their intended use was collected. Because of variability in the study populations, study designs, and outcomes, a descriptive analysis of data was performed.

\section{Characteristics of included studies and patient populations}

Characteristics of the studies reported in the selected articles are summarized in Table 1. Five articles discussed the results of randomized studies. ${ }^{26-30} \mathrm{~A}$ majority were nonrandomized, single-arm studies $(n=11),{ }^{18,31-40}$ and two were parallel-arm studies. ${ }^{41,42}$ A total of 1,000 participants were recruited across the selected studies. The studies included patients diagnosed with schizophrenia and/or schizoaffective disorder $(\mathrm{n}=9),{ }^{18,31-33,35,36,39-41}$ bipolar disorder $(\mathrm{n}=5),{ }^{18,26,34,37,38}$ MDD $(n=2),{ }^{28,30}$ and psychotic disorder with suicidality $(n=2) .27,42$ Where reported, patients' mean disease duration ranged from 6 to 19 years. A majority of the studies were conducted in predominantly male population, with the exception of two studies, in which $\sim 70 \%$ of the study sample was female..$^{26,28}$ Study duration ranged from 2 hours for usability testing ${ }^{33}$ to over 1 year, ${ }^{27}$ participants were followed for $\geq 1$ year in only three studies. ${ }^{26,27,37}$ Either the study completion rate or adherence to the technology was reported. Overall, the study completion rate was high across the selected studies

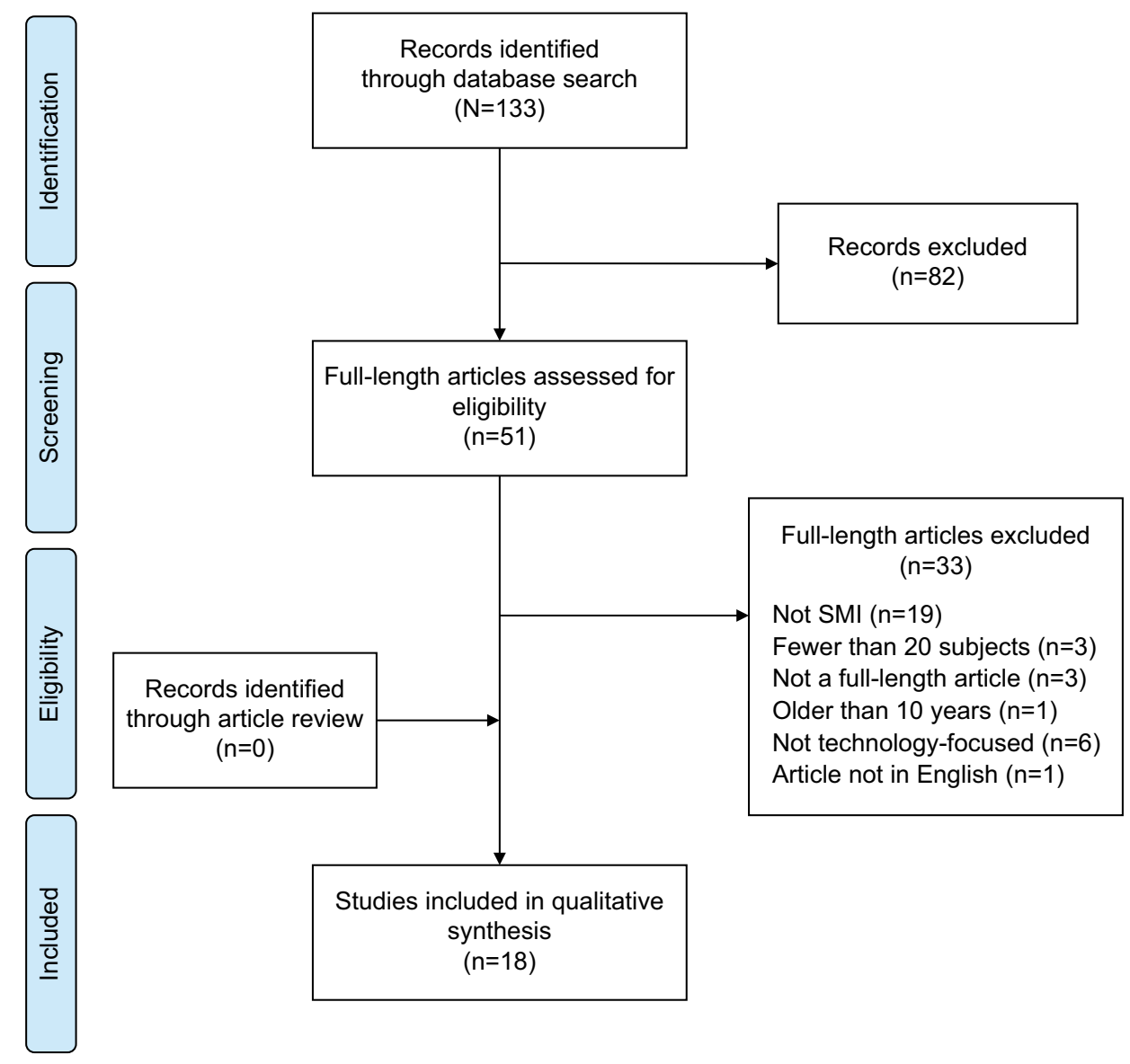

Figure I Article selection process. Abbreviation: SMI, serious mental illness. 
Table I Study characteristics of selected articles

\begin{tabular}{|c|c|c|c|c|c|c|}
\hline Study & Design & Location & Population diagnosis (n) & Duration & Digital technology & Completion rate \\
\hline \multicolumn{7}{|c|}{ Randomized studies } \\
\hline $\begin{array}{l}\text { Faurholt-Jepsen } \\
\text { et } \mathrm{a}^{26}\end{array}$ & $\begin{array}{l}\text { Randomized, } \\
\text { controlled }\end{array}$ & Denmark & $\begin{array}{l}\text { Bipolar I and II disorder (33) } \\
\text { - } 71 \% \text { women, illness } \\
\text { duration } 9.8 \text { years }\end{array}$ & 6 months & $\begin{array}{l}\text { MONARCA } \\
\text { smartphone app for } \\
\text { monitoring }\end{array}$ & $\begin{array}{l}\text { Mean use of the } \\
\text { system } 93 \%\end{array}$ \\
\hline Forchuk et $\mathrm{al}^{27}$ & $\begin{array}{l}\text { Randomized, } \\
\text { mixed-method, } \\
\text { qualitative }\end{array}$ & Canada & $\begin{array}{l}\text { Mood or psychotic disorder } \\
\text { (95) }\end{array}$ & $12-18$ months & $\begin{array}{l}\text { Lawson SMART } \\
\text { record, a } \\
\text { smartphone- } \\
\text { and iPad-based } \\
\text { electronic personal } \\
\text { health record }\end{array}$ & $99 \%$ \\
\hline Ly et $\mathrm{al}^{28}$ & $\begin{array}{l}\text { Randomized, } \\
\text { open-label }\end{array}$ & Sweden & $\begin{array}{l}\text { Major depressive disorder and } \\
\text { depression }(81) \\
\text { - } 70 \% \text { women, } 63 \% \text { college } \\
\text { educated, } 80 \% \text { employed/ } \\
\text { studying }\end{array}$ & 8 weeks & $\begin{array}{l}\text { Smartphone app for } \\
\text { psychoeducation for } \\
\text { behavior activation } \\
\text { and mindfulness } \\
\text { intervention }\end{array}$ & $85.2 \%$ \\
\hline Velligan et $\mathrm{a}^{29}$ & $\begin{array}{l}\text { Randomized, } \\
\text { controlled }\end{array}$ & USA & $\begin{array}{l}\text { Schizophrenia or } \\
\text { schizoaffective disorder (132) } \\
\text { - } \quad 50 \% \text { men }\end{array}$ & 9 months & $\begin{array}{l}\text { PharmCAT, Med- } \\
\text { eMonitor, and } \\
\text { treatment-as-usual }\end{array}$ & $82 \%$ \\
\hline Watts et $\mathrm{al}^{30}$ & $\begin{array}{l}\text { Randomized, } \\
\text { controlled }\end{array}$ & Australia & $\begin{array}{l}\text { Major depressive disorder } \\
\text { (35) } \\
\text { - } 80 \% \text { women }\end{array}$ & 3 months & $\begin{array}{l}\text { Get Happy Program, } \\
\text { a mobile app version } \\
\text { of clinician-assisted } \\
\text { treatment program }\end{array}$ & $68.6 \%$ \\
\hline \multicolumn{7}{|c|}{ Nonrandomized studies } \\
\hline Ben-Zeev ${ }^{32}$ & $\begin{array}{l}\text { Nonrandomized, } \\
\text { single-arm }\end{array}$ & USA & $\begin{array}{l}\text { Schizophrenia or } \\
\text { schizoaffective disorder ( } 24) \\
\text { - Mild positive and negative } \\
\text { symptoms } \\
\text { - } 71 \% \text { men, } ~ 75 \% \text { high } \\
\text { school-graduated or higher, } \\
\text { illness duration } 17 \text { years }\end{array}$ & I week & $\begin{array}{l}\text { Mobile EMA } \\
\text { software package }\end{array}$ & $100 \%$ \\
\hline Ben-Zeev et al ${ }^{41}$ & $\begin{array}{l}\text { Nonrandomized, } \\
\text { parallel-arm }\end{array}$ & USA & $\begin{array}{l}\text { Schizophrenia or } \\
\text { schizoaffective disorder (24) } \\
\text { and nonclinical (26) } \\
\text { - Mild psychotic symptoms, } \\
\text { illness duration } 17 \text { years } \\
\text { - } 71 \% \text { men in experimental } \\
\text { group, } 65 \% \text { women in } \\
\text { control group }\end{array}$ & I week & $\begin{array}{l}\text { Mobile EMA } \\
\text { software package }\end{array}$ & $100 \%$ \\
\hline Ben-Zeev et $\mathrm{al}^{33}$ & $\begin{array}{l}\text { Nonrandomized, } \\
\text { single-arm }\end{array}$ & USA & $\begin{array}{l}\text { Schizophrenia or } \\
\text { schizoaffective disorder }(12)^{\mathrm{a}} \\
\text { - } 67 \% \text { men } \\
\text { - } \sim 50 \% \text { had less than high- } \\
\text { school diploma }\end{array}$ & $2 \mathrm{~h}$ & $\begin{array}{l}\text { FOCUS, a } \\
\text { smartphone app }\end{array}$ & $100 \%$ \\
\hline Ben-Zeev et a ${ }^{31}$ & $\begin{array}{l}\text { Nonrandomized, } \\
\text { single-arm }\end{array}$ & USA & $\begin{array}{l}\text { Schizophrenia or } \\
\text { schizoaffective disorder (32) } \\
\text { - } 61 \% \text { men, average } \\
\text { education level eighth grade } \\
\text { - Moderate illness severity at } \\
\text { baseline }\end{array}$ & I months & $\begin{array}{l}\text { FOCUS, a system } \\
\text { comprising three } \\
\text { smartphone apps }\end{array}$ & $97 \%$ \\
\hline Depp et $\mathrm{al}^{38}$ & Nonrandomized & USA & $\begin{array}{l}\text { Bipolar I or II (4I) } \\
\text { - Patients had mild illness }\end{array}$ & II weeks & $\begin{array}{l}\text { Smartphone app for } \\
\text { EMA of mood and } \\
\text { related experiences }\end{array}$ & $\begin{array}{l}\text { Adherence to the } \\
\text { program } 65.1 \%\end{array}$ \\
\hline $\begin{array}{l}\text { Hidalgo-Mazzei } \\
\text { et al }{ }^{34}\end{array}$ & $\begin{array}{l}\text { Nonrandomized, } \\
\text { single-arm }\end{array}$ & Spain & $\begin{array}{l}\text { Bipolar disorder (49) } \\
\text { - Patients were euthymic } \\
\text { - } 57 \% \text { men, } 61 \% \text { high } \\
\text { education level } \\
\text { - Illness duration, } 12.7 \text { years }\end{array}$ & 3 months & $\begin{array}{l}\text { SIMPLe smartphone } \\
\text { app to collect EMAs }\end{array}$ & $\begin{array}{l}\text { App use } 94 \% \text { at } \\
\text { I month, } 82 \% \text { at } \\
2 \text { months, and } 74 \% \\
\text { at } 3 \text { months }\end{array}$ \\
\hline
\end{tabular}


Table I (Continued)

\begin{tabular}{|c|c|c|c|c|c|c|}
\hline Study & Design & Location & Population diagnosis (n) & Duration & Digital technology & Completion rate \\
\hline Husky et $\mathrm{a}^{42}$ & $\begin{array}{l}\text { Nonrandomized, } \\
\text { parallel-arm }\end{array}$ & France & $\begin{array}{l}\text { Mood disorder with suicidality } \\
\text { (83) and healthy controls (13) } \\
\text { - } 73.8 \% \text { women in recent } \\
\text { suicide-attempt group, all } \\
\text { women in other groups }\end{array}$ & I week & $\begin{array}{l}\text { EMA delivered via a } \\
\text { mobile device (PDA) }\end{array}$ & $\begin{array}{l}73.8 \% \text { in } \\
\text { experimental group, } \\
85.7 \% \text { in the control } \\
\text { group }\end{array}$ \\
\hline Kane et al ${ }^{18}$ & $\begin{array}{l}\text { Nonrandomized, } \\
\text { single-arm, } \\
\text { observational }\end{array}$ & USA & $\begin{array}{l}\text { Schizophrenia and bipolar } \\
\text { disorder (28) } \\
\text { - } 64 \% \text { men, majority had } \\
\text { completed high school or } \\
\text { college }\end{array}$ & 4 weeks & $\begin{array}{l}\text { DHFS, which } \\
\text { electronically } \\
\text { confirms ingestion } \\
\text { of oral medication } \\
\text { embedded with an } \\
\text { ingestion sensor } \\
\text { and acquires } \\
\text { physiological metrics }\end{array}$ & $96 \%$ \\
\hline Moore et $\mathrm{al}^{39}$ & $\begin{array}{l}\text { Nonrandomized, } \\
\text { observational }\end{array}$ & USA & $\begin{array}{l}\text { Schizophrenia/schizoaffective } \\
\text { disorder (2I) and healthy } \\
\text { controls (I3) }\end{array}$ & I visit & $\begin{array}{l}\text { Mobile app } \\
\text { version of a scale } \\
\text { for functioning } \\
\text { capacity assessment } \\
\text { (UPSA-M) }\end{array}$ & NS \\
\hline Osipov et $\mathrm{a}^{35}$ & $\begin{array}{l}\text { Nonrandomized, } \\
\text { observational }\end{array}$ & NS & $\begin{array}{l}\text { Healthy adults (19), } \\
\text { schizophrenia (16) } \\
\text { - Patients were in relative } \\
\text { symptomatic remission } \\
\text { - } 58 \% \text { men in schizophrenia } \\
\text { group and } 75 \% \text { in control } \\
\text { group } \\
\text { - Illness duration } 6.4 \text { years }\end{array}$ & 4 weeks & $\begin{array}{l}\text { Adhesive patch to } \\
\text { monitor locomotor } \\
\text { activity and heart } \\
\text { rate paired to a } \\
\text { mobile device }\end{array}$ & NS \\
\hline $\begin{array}{l}\text { Palmier-Claus } \\
\text { et } \mathrm{al}^{40}\end{array}$ & $\begin{array}{l}\text { Nonrandomized, } \\
\text { observational }\end{array}$ & UK & $\begin{array}{l}\text { Schizophrenia and related } \\
\text { disorders (44) } \\
\text { - } 77.8 \% \text { men }\end{array}$ & I week & $\begin{array}{l}\text { ClinTouch, a mobile } \\
\text { app for assessment } \\
\text { of mood symptoms }\end{array}$ & $\begin{array}{l}\text { Met criteria for } \\
\text { compliance with } \\
\text { methodology } 82 \%\end{array}$ \\
\hline $\begin{array}{l}\text { Peters-Strickland } \\
\text { et } \mathrm{al}^{36}\end{array}$ & $\begin{array}{l}\text { Nonrandomized, } \\
\text { Phase II, open- } \\
\text { label }\end{array}$ & USA & $\begin{array}{l}\text { Schizophrenia (49) } \\
\text { - Majority of patients mildly } \\
\text { ill } \\
\text { - } 74.6 \% \text { men } \\
\text { - Illness duration } 19.3 \text { years }\end{array}$ & 8 weeks & $\begin{array}{l}\text { Digital medicine } \\
\text { system comprising } \\
\text { medication } \\
\text { embedded with an } \\
\text { ingestible sensor, } \\
\text { a wearable sensor, } \\
\text { and software apps }\end{array}$ & $73.1 \%$ \\
\hline Tsanas et $\mathrm{al}^{37}$ & $\begin{array}{l}\text { Nonrandomized, } \\
\text { observational }\end{array}$ & UK & $\begin{array}{l}\text { Bipolar disorder or borderline } \\
\text { personality disorder and } \\
\text { healthy controls }(130) \\
\text { - } 74 \% \text { women in } \\
\text { experimental group }\end{array}$ & 3 months & $\begin{array}{l}\text { Smartphone app } \\
\text { Mood Zoom, a } \\
\text { clinical questionnaire } \\
\text { for daily mood } \\
\text { monitoring }\end{array}$ & $\begin{array}{l}\text { Adherence to } \\
\text { program } 87 \%-93 \% \\
\text { at } 3 \text { months }\end{array}$ \\
\hline
\end{tabular}

Note: a904 participated in the stage I needs assessment part of the study.

Abbreviations: App, application; DHFS, digital health feedback system; EMA, ecological momentary assessment; NS, not specified; PDA, personal digital assistant; UPSA-M, University of California, San Diego performance-based skills assessment - mobile.

(Table 1). Five studies assessed the usability and feasibility of DHTs, ${ }^{27,33,34,36,42}$ three tested feasibility and validity, ${ }^{37,39,40}$ eight evaluated efficacy or effectiveness, ${ }^{26,28-30,32,35,38,41}$ and two evaluated both usability and effectiveness. ${ }^{18,31}$ In all but three studies, ${ }^{28,35,37}$ training or support was provided during initial use of the technologies.

\section{Characteristics of digital health technologies}

The DHTs evaluated across the studies could be broadly classified as mobile/smartphone apps $(n=14)$, digital medicine $(n=2)$, adhesive patches paired with mobile devices $(n=1)$, or electronic pill containers $(n=1)$. Key findings from the studies are described in Table 2. The majority of DHTs described in the selected studies (14 of 18 [77.8\%]) were mobile/smartphone apps that collected patient data in real time. In five studies, mobile device apps were used to collect ecological momentary assessments (EMAs). ${ }^{32,34,38,41,42}$ In three studies, smartphone apps were used for daily mood and symptom monitoring. ${ }^{26,37,40}$ One study tested a mobile version of a skill assessment scale for assessing functional capacity of patients. ${ }^{39}$ Forchuk et al evaluated the Mental 


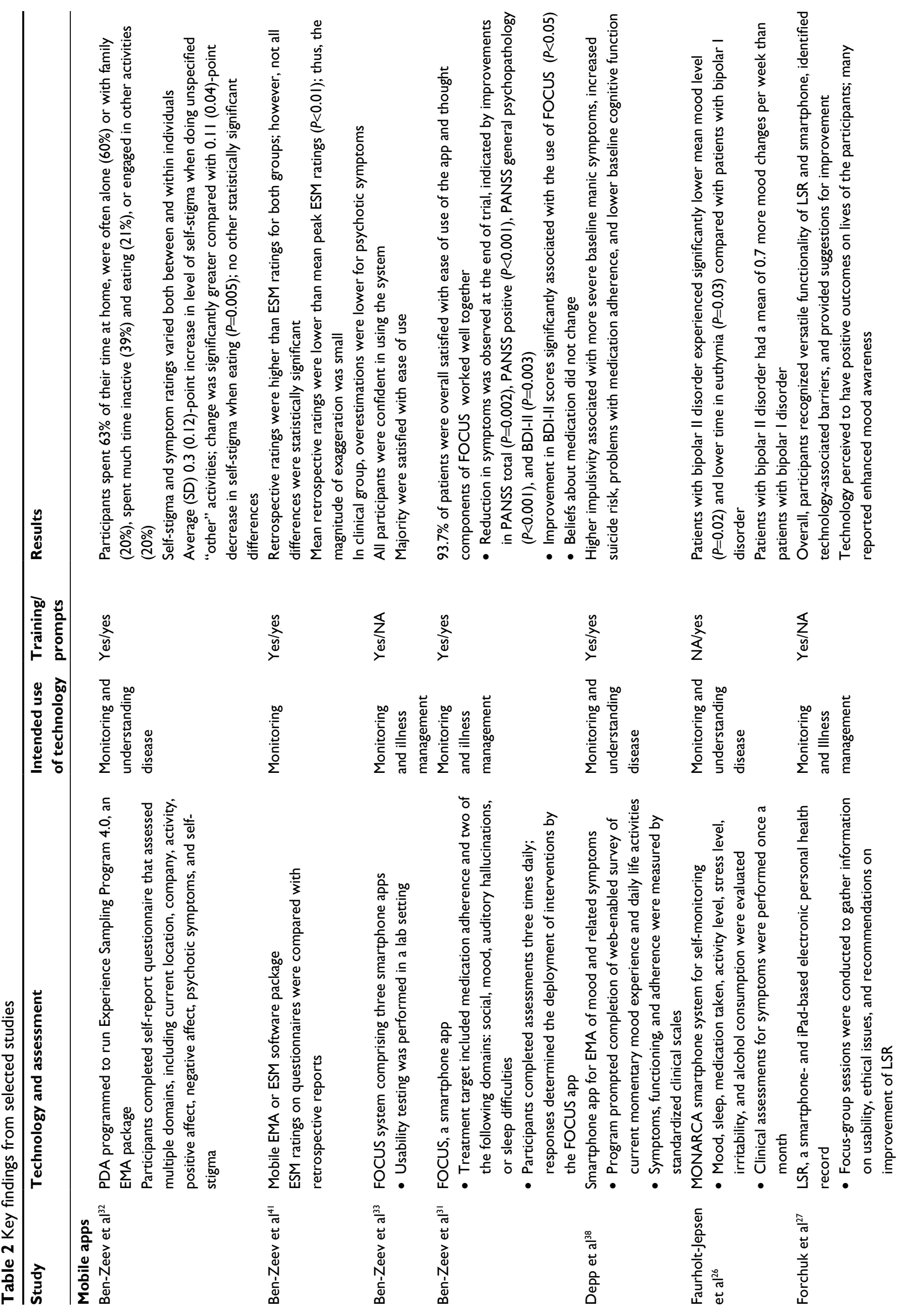



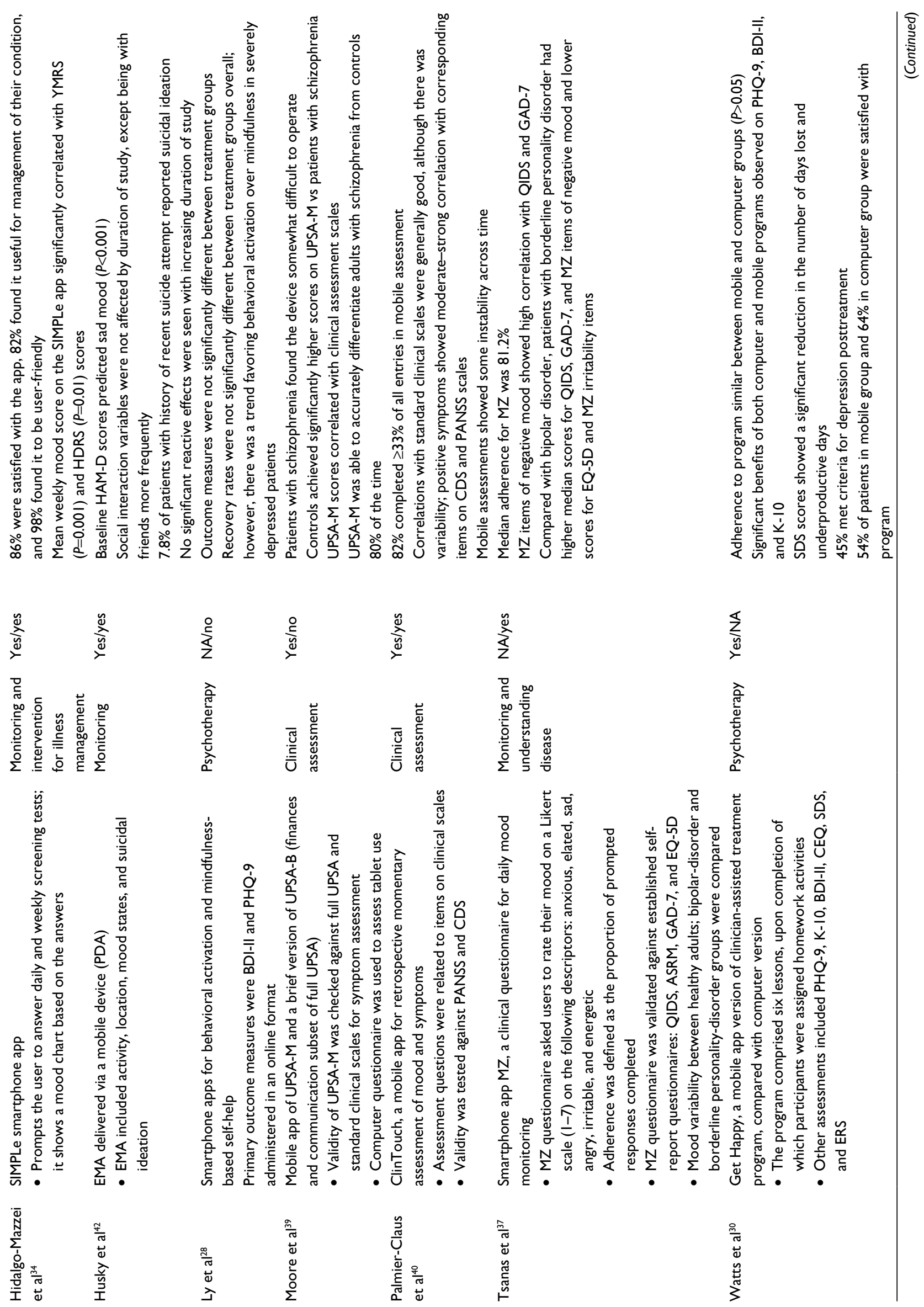


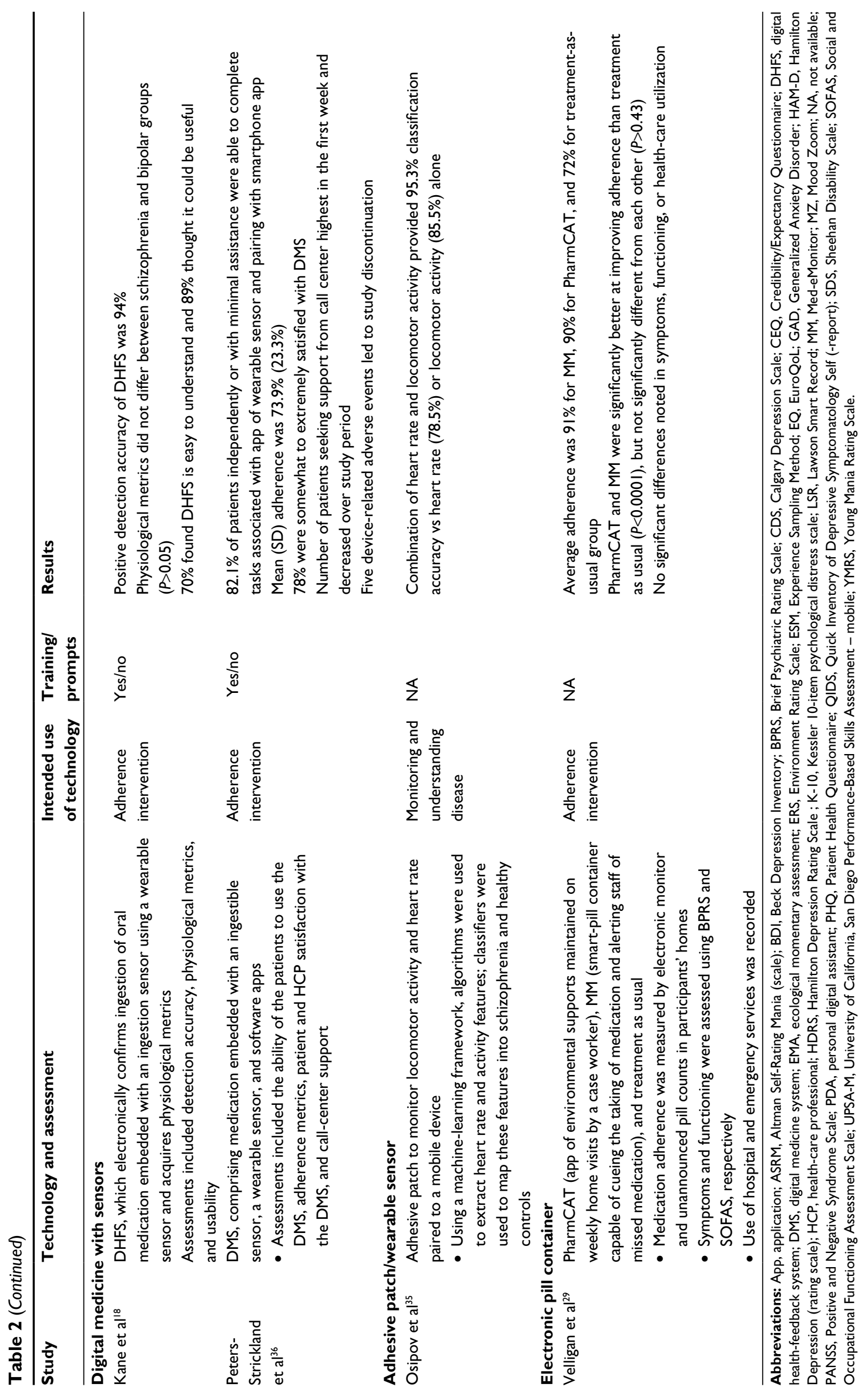


Health Engagement Network, a web-based electronic personal health record and smartphone intervention. ${ }^{27}$ The purpose of the program was to help patients self-manage their illness and improve their communications with care providers. Smartphones were used to deliver psychosocial/ behavioral therapy in four studies. ${ }^{28,30,31,33} \mathrm{~A}$ frequently used format in smartphone apps was completion of self-reports or questionnaires when prompted by an auditory signal generated by the app. ${ }^{26,32-34}$ These questionnaires aimed to assess domains, such as mood, sleep, activity, and symptoms.

Two studies described the development of a digital medicine system that consisted of oral medication embedded with an ingestible event marker, a wearable sensor that detected the ingestion, and smartphone apps that allowed collection and sharing of data. ${ }^{18,36}$ The wearable sensor also collected physiological metrics. In one study, an adhesive patch that continuously monitored locomotor activity and heart rate was paired with a mobile phone to collect and save data to a secure server. ${ }^{35}$ In another example of digital technology for use in psychiatry, a randomized study compared the efficacy of an electronic smart-pill container, Med-eMonitor (MM; InforMedix, Rockville, MD, USA), with other interventions for improving patients' medication adherence. ${ }^{29}$ The MM was programmed and set up by a therapist in the patient's home to prompt the patient to take his or her medication, while recording missed medication and side effects.

\section{Usability and effectiveness of health technologies}

As previously mentioned, usability is of particular interest in technologies used by patients with SMI. Four studies reported following a user-centered design approach: ${ }^{30,31,33,34}$ one study indicated that the program was not specifically designed for the intended user, ${ }^{28}$ and the rest did not specify their design approach.

Eight studies included in the analysis tested the usability or feasibility of digital tools and technologies in the target population of patients with SMI. In 2-hour laboratorybased usability testing, after a brief tutorial all patients with schizophrenia were able to learn to use the FOCUS system, ${ }^{33}$ which comprised three apps installed on a smartphone. Additionally, a majority of users found the system easy to use and considered it helpful. ${ }^{33}$ After refinement of some of the features based on user recommendations, the usability of FOCUS was further confirmed in a field trial, in which patients with schizophrenia used the system in their day-today surroundings for $>1$ month. ${ }^{31}$ Preliminary assessment of efficacy showed that use of the FOCUS system was associated with reduction in positive symptoms, general symptoms of psychopathology, and depression. Similarly, in another study, patients with mood or psychotic disorders found the use of a mobile personal health record engaging, and believed that its use had a positive effect on their lives. ${ }^{27}$ Study participants also suggested improvements to the functionality of the program. In a study testing the usability of the SIMPLe app, which monitors symptoms and offers personalized psychoeducation, $98 \%$ of patients with bipolar disorder considered its use to be simple and $82 \%$ considered it relevant to self-management of their condition. ${ }^{34}$ However, the use of the app decreased over time; the number of active users dropped from $94 \%$ at 1 month to $74 \%$ at 3 months. The feasibility of ClinTouch, another smartphone app for monitoring symptoms, was demonstrated in a group of patients with schizophrenia and related disorders. ${ }^{40}$

The feasibility and acceptability of a digital medicine system was assessed in two studies. In a pilot two-site study that recruited patients with schizophrenia, Kane et al demonstrated 94\% positive detection accuracy with a digital health feedback system (DHFS) when compared with directly observed ingestions. ${ }^{18}$ Of the users, $70 \%$ found the DHFS concept easy to understand, and $89 \%$ considered it useful. In the other study, $82 \%$ of patients were able to complete various tasks associated with the use of the digital medicine system independently or with minimal assistance. ${ }^{36}$ Overall, $78 \%$ of patients were satisfied with the system, and $65 \%$ found it to be somewhat easy, easy, or extremely easy to use. Husky et al demonstrated the feasibility of using mobile EMA in monitoring suicidal ideation. ${ }^{42}$ Study acceptance rates were high: $66.7 \%-87.5 \%$ across the different study groups. Overall, compliance with the EMA procedures was $73.8 \%-85.7 \%{ }^{42}$

The effectiveness of smartphone-delivered behavioral and mindfulness treatments for MDD was demonstrated in a randomized controlled trial. ${ }^{28}$ Although the benefits of the two programs were not different overall from each other, subgroup analysis indicated that behavioral activation had a more favorable effect for patients with a higher severity of depression, whereas a mindfulness program was more effective for mildly depressed patients. Overall adherence to the entire treatment was $70 \%$. Another randomized study compared the efficacy of a mobile format of CBT for major depression with a computer format. ${ }^{30}$ Both formats of the intervention resulted in significant benefits, indicated by scores on clinical assessment scales. Overall adherence to the programs was similar, with $68.6 \%$ of participants completing all assessments. Among the users, 54\% in the mobile 
group and $64 \%$ in the computer group were very satisfied with the program.

Velligan et al compared the effectiveness of the smart-pill container MM with the Pharmacogenomics Clinical Annotation Tool (PharmCAT; a subset of techniques from cognitive adaptation training) and treatment as usual to improve medication adherence in patients with schizophrenia. ${ }^{29}$ Both the MM and PharmCAT significantly improved adherence compared with treatment as usual. However, study dropout rates were higher in the MM group.

\section{Intended use of digital health technologies}

The primary intended uses of DHTs included in the selected studies were monitoring to gain an understanding of disease, clinical assessment, and intervention. Interventions were further divided into illness self-management, adherence intervention, and psychoeducation/CBT (Figure 2).

\section{Use of digital health technologies for monitoring}

All the tools intended for patient monitoring employed smartphone apps. Ben-Zeev et al conducted two studies with a mobile device programmed to run experience sampling, an EMA package. ${ }^{32}$ The program generated auditory prompts for completing a self-report questionnaire that assessed various domains in real time. One study examined the relations among external/contextual factors, illness symptoms, and self-stigma in patients with schizophrenia or schizoaffective disorder. Activity was found to be a significant predictor of change in self-stigma. In the other study, average ratings of mobile MAs were found to be comparable to those from retrospective reports, with the added dimension of variability in experience over time. ${ }^{41}$ Together, both studies demonstrated the utility of mobile EMA in monitoring disease symptoms.

Another mobile device-based EMA app asked users to describe their social interaction variables, such as location, activity, and social company. Users also rated their mood states and noted any negative feelings. ${ }^{42}$ It has been hypothesized that repeated questioning about negative cognition may be harmful for participants and eventually contribute to suicide risk, a phenomenon referred to as reactive effect. However, in people at risk of suicide, no increase in reactive effects was observed with increasing duration of mobile assessments in this study.

Three studies described mobile device-based monitoring programs developed for patients with bipolar disorder. MONARCA (monitoring, treatment, and prediction of bipolar disorder episodes $)^{26}$ is a smartphone app for daily monitoring of such variables as mood, sleep, activity level, and stress level in real time. In a randomized study, daily electronic self-monitoring data from MONARCA was used to differentiate between bipolar-I disorder (BP-I) and bipolar-II disorder (BP-II). ${ }^{26}$ Patients with BP-II showed more mood fluctuations than those with BP-I. Mood Zoom (MZ), ${ }^{37} \mathrm{a}$ clinical questionnaire, was also developed as a smartphone app for longitudinal assessment of mood symptoms in patients with bipolar disorder. Users were asked to assess their mood using the predefined descriptors anxious, elated, sad, angry, irritable, and energetic.

In an observational study, the $\mathrm{MZ}$ questionnaire was able to differentiate between bipolar disorder and borderline personality disorder, with borderline personality disorder showing greater variability in mood scores, particularly for irritability. ${ }^{37}$ Scores on MZ items were validated against established self-

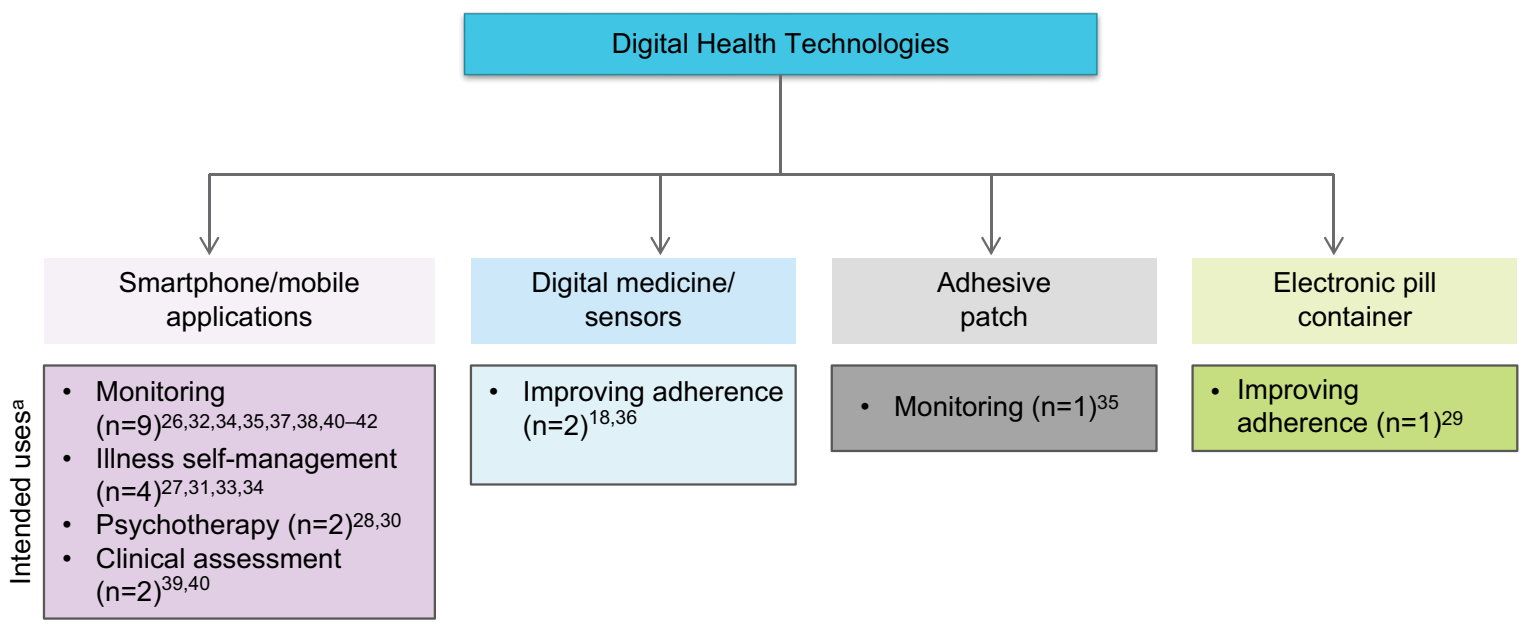

Figure 2 Digital health technologies and their intended uses.

Note: ${ }^{a}$ Digital technologies may have had more than one intended use. 
report questionnaires. In the third example of a smartphonebased app for monitoring patients with bipolar disorder, users completed a web-enabled survey of current momentary mood and related experiences. ${ }^{38}$ The data were used to assess impulsivity. Higher impulsivity was associated with greater manic symptoms, suicide risk, and adherence problems.

A disposable adhesive patch paired to a mobile phone was developed to collect electrocardiogram-derived heart rate and accelerometry-derived locomotor data in patients with schizophrenia. ${ }^{35}$ In a study conducted to identify predictors of schizophrenia compared with healthy controls, a combination of locomotor activity and heart rate provided better classification accuracy than either feature alone for predicting schizophrenia.

\section{Use of digital health technologies for clinical assessment}

Two studies reported on smartphone apps used for clinical assessments. Moore et al developed a mobile app version of University of California, San Diego Performance-Based Skills Assessment - mobile (UPSA-M) for evaluating the functional capacity of patients with schizophrenia. ${ }^{39}$ A tutorial and user manual were provided to familiarize patients with the app, following which the app was administered at a visit with minimal examiner involvement. Findings from the study demonstrated that UPSA-M correlated well with the standardized clinical assessment scale and was able to differentiate between healthy adults and patients with schizophrenia $80 \%$ of the time. In another study, a smartphone-based self-report assessment scale for psychosis was developed, which included items that were designed to be equivalent to some items on standard clinical assessment scales. ${ }^{40}$ The majority of symptom scores collected with the app showed good correlation with standard clinical symptom scales and were internally consistent. Additionally, the scores were sensitive to shifts in symptomatology across time.

\section{Use of digital health technologies for intervention Illness self-management}

Three programs have been designed to assist SMI patients with self-management of their illness. The first of these FOCUS, a smartphone app for illness management - was evaluated in two studies. ${ }^{31,33}$ Users were asked to self-assess several domains, such as adherence, mood, sleep, social functioning, and coping with symptoms. Targeted illness management interventions were suggested based on the domains that were "flagged". The program also included on-demand resources for illness management. Additionally, users could share data with their health-care providers. During the usability study, participants used some of the coping strategies suggested by the program. ${ }^{33}$

The second DHT intended for illness self-management comprised an electronic personal health record with a smartphone intervention that was tested in a group of patients with mood or psychotic disorders to help them manage their mental health. ${ }^{27}$ Users considered features of the program useful, such as a mood-tracking function and appointment reminders. Some users described enhanced self-awareness due to mood tracking. However, the authors noted that simply owning a smartphone (provided by the investigators) might have biased the users' positive perception of the intervention program. The third smartphone app for enabling self-management of bipolar disorder was SIMPLe, which detected mood changes based on EMA and offered psychoeducational messages to cope with the situation. ${ }^{34}$ Mean mood scores generated by the app showed significant correlation with standardized clinical scales of mania and depression.

\section{Medication adherence}

Three studies described the use of DHTs for improving medication adherence in patients with schizophrenia and bipolar disorder. Of these, two reported the development of digital medicine systems to measure medication ingestion objectively and acquire physiological metrics. ${ }^{18,36}$ In a 4-week observational study in patients with schizophrenia or bipolar disorder, positive detection accuracy with the DHFS was $94 \%$ when compared with directly observed ingestions. Physiological metrics did not show any significant differences between patients with schizophrenia and bipolar disorder. ${ }^{18}$ The mean adherence estimate obtained with a digital medicine system in an 8-week usability study was $73.9 \%{ }^{36}$ A randomized trial compared PharmCAT and the MM with treatment as usual for improving medication adherence in patients with schizophrenia. ${ }^{29}$ The study examined adherence, symptoms, and functioning over 3, 6, and 9 months. Average adherence was $90 \%$ and $91 \%$ with PharmCAT and MM, respectively, compared with $72 \%$ for the treatment-as-usual group. Improved adherence, however, was not associated with improvements in symptoms or functioning.

\section{Therapy}

Two randomized controlled trials investigated the use of smartphone apps to deliver psychotherapy to patients with MDD. Ly et al compared behavioral activation with mindfulness treatment delivered via smartphones. ${ }^{28} \mathrm{~A}$ behavioractivation app included a database of 54 behaviors for the 
user to perform and reflect on. Behavior data were available to the therapist, who could send encouraging messages to the patient. At the 6-month follow-up, patients with higher severity of depression benefited more from behavioral activation, whereas mindfulness was more effective for patients with mild symptoms.

Watts et al compared a mobile format of CBT, the Get Happy program, with a computer format. ${ }^{30}$ The program consisted of lessons in the form of a comic book that narrated case stories, after completion of which users were assigned homework activities. At the end of the study, both mobile and computer formats of the program were associated with significant improvement in symptoms, as indicated by standardized clinical scales for measuring symptoms.

\section{Discussion}

A review of the selected studies identified mobile apps, an electronic pill container, a personal DH record, digital medicine, and wearable sensors as DHTs being explored for use in people with SMI. Mobile/smartphone apps were the most common among the digital technologies being developed, and the most common intended use of DHTs was patient monitoring. Overall, the selected studies indicated high feasibility and acceptability of technologies for mental health care. The studies also demonstrated the potential applicability of these technologies in monitoring symptoms to gain a better understanding of disease, providing psychotherapy, assessing or improving medication adherence, and assessing clinical symptoms.

Testing usability in target users is particularly critical for developing digital tools for patients with SMI, because mental illness-related factors, such as cognitive impairments, can limit the use of DHTs in this population. ${ }^{10,43}$ As suggested by Rotondi et al, ${ }^{10}$ the needs of users with SMI differ from those of the general population, and DHTs that reduce the cognitive effort required on the part of users may be more appropriate for persons with SMI. However, it is noteworthy that most of the studies reviewed here did not specify following a usercentered approach for designing the DHT. This underscores the need for further emphasis on tailoring the design elements to user needs. Additionally, a large number of the selected studies included patients with mild illness severity. Although the selection of less impaired subjects is essential to rule out the effect of impairments on technology use, it is important to test usability in a population more representative of the real world to improve generalizability of the results.

In addition, the characteristics of patients included in the studies differed from one another and may have differed from the intended user populations. Whether sex differences affect the use of DHTs for mental health is not known, but the study populations were predominantly male. In an online survey, women were more engaged than men in finding healthrelated information on the web, whereas men more frequently used apps. ${ }^{44}$ Education level may also affect the use of and receptivity to health technology. The education level of participants varied between studies, ranging from eighth grade to college. In addition, most of the studies were conducted in small populations under controlled conditions. Collectively, the results may not be generalizable to patients encountered in routine clinical practice. Nevertheless, reviewed studies overall indicated high feasibility and usability of DHTs among patients with SMI, at least those with mild-moderate disease severity. This is consistent with findings in other reviews. ${ }^{16,24}$

Study completion rates and adherence to the technology were high among the selected studies, when reported. However, in the study by Hidalgo-Mazzei et al, use of the SIMPLe app decreased over time. ${ }^{34}$ This highlights challenges with sustained user engagement and should be kept in mind when designing DHTs for mental health. Several apps used auditory prompts to remind users of assessments. In a published systematic review, various means of prompts were shown to be helpful in promoting engagement with digital technologies, ${ }^{45}$ thus suggesting that this might be a useful feature to incorporate into the functionality of a DHT.

The majority of DHTs assessed in the selected studies were mobile apps. Mobile apps offer novel approaches, such as real-time monitoring of mental and physical health variables and remote access to information for patients and providers. Such information has the potential to improve our understanding of the illness and offers an opportunity to intervene in a timely manner when predictors of disease worsening are identified. Indeed, several studies noted a correlation between mobile self-assessments and disease symptoms. ${ }^{26,34,35,37,38,41,46}$ For example, higher impulsivity was shown to be associated with worse baseline cognitive function, prior suicide attempts, medication-adherence problems, and more severe manic symptoms. ${ }^{38}$ Mobile apps also allow patients access to therapy outside in-person treatment sessions. Two studies demonstrated the efficacy of delivering psychotherapy via mobile apps. ${ }^{28,30}$ However, a previously published systematic literature review found little evidence to support the efficacy of CBT apps, ${ }^{23}$ although a computerized version was found to be effective for anxiety and depression. ${ }^{16}$ Where evaluated, good correlation between mobile assessment scores and standard clinical assessments was observed, supporting the clinical applicability of the apps. ${ }^{37,39,40}$ Further 
support was provided by a Cochrane review that evaluated questionnaire responses obtained from mobile apps and found them to be equivalent to other modes of delivery. ${ }^{47}$ Additionally, records from apps were more complete than paper. However, for implementation in clinical practice, standardization of various assessments and their interpretation needs to be established.

Digital technology holds promise to overcome other barriers in mental health. For example, obtaining an accurate measure of medication adherence can be challenging in clinical practice ${ }^{48}$ However, wearable sensors enable measurements of accurate, real-time estimates of medication ingestion. ${ }^{18,36}$ The data provided by these technologies may allow for more informed treatment decisions and potentially avoid unnecessary medication changes.

The duration of most studies reviewed here was short. Therefore, there was a lack of sufficient data on long-term use of DHTs for mental health. Results obtained for the short term look promising, but whether the large volume of data obtained from DHTs can indeed transform mental health care and improve patient outcomes remains to be determined. Considering the rapid proliferation of health technologies and increasingly widespread adoption, digital technologies have the potential to change the nature of clinical practice and health care. However, to integrate them into a health-care delivery system, clinicians need an evidence base that demonstrates the effectiveness of these technologies in improving the outcomes in larger patient populations. In a systematic review and meta-analysis of digital health interventions for children and young people with mental health disorders, Hollis et al noted a clinical benefit, particularly for computerized CBT for depression and anxiety. ${ }^{49}$ However, the authors did not find quality evidence to support the clinical benefit of technology in attention deficit/hyperactivity disorder, autism, psychosis, or eating disorders. Other systematic reviews have also pointed out that scientific evidence to support the efficacy of technology interventions is inadequate. ${ }^{22-24}$ Most DHTs are tested in pilot studies in a small population under controlled conditions, as also evidenced in this review. Additionally, owing to a lack of standardized evaluation and reporting, comparison of technologies is challenging.

Several efforts based on literature reviews and surveys of experts in the field have been undertaken to standardize the quality of evidence for mHealth interventions. The World Health Organization mHealth Technical Evidence Review Group recently developed a checklist of items for developing and reporting mHealth interventions. ${ }^{50}$ CONSORT-eHealth (Consolidated Standards of Reporting Trials of electronic and
mHealth applications and online telehealth) is another tool recommended for use in reporting web-based and mHealth interventions. ${ }^{51}$ Bakker et al provided evidence-based recommendations for developing smartphone apps for mental health. ${ }^{52}$ These initiatives should lead to harmonization of evaluation and reporting methods, thus allowing clinicians to better understand and compare options to make informed choices.

\section{Conclusion}

There are increasing numbers of DHTs available for use in persons with SMI. Studies summarized in this review indicate that overall short-term usability and feasibility of technology are high in the SMI population, suggesting the potential utility of digital technology for incorporation into treatment of SMI. Real-world, naturalistic studies using larger samples will further facilitate the integration of digital technology into everyday mental health care.

\section{Acknowledgments}

Editorial support for development of this manuscript was provided by Vandana Sharma, $\mathrm{PhD}$, at C4 MedSolutions LLC (Yardley, PA), a CHC Group company, and funded by Otsuka Pharmaceutical Development and Commercialization Inc.

\section{Disclosure}

$\mathrm{SB}$ is a pharmaceutical medicine fellow at Rutgers Robert Wood Johnson Medical School. RAB, TW, FF, FD, and TPS are employees of Otsuka Pharmaceutical Development and Commercialization Inc. The authors report no other conflict of interest in this work.

\section{References}

1. Whiteford HA, Ferrari AJ, Degenhardt L, Feigin V, Vos T. The global burden of mental, neurological and substance use disorders: an analysis from the Global Burden of Disease Study 2010. PLoS One. 2015;10(2):e0116820.

2. Huxley CJ, Atherton H, Watkins JA, Griffiths F. Digital communication between clinician and patient and the impact on marginalised groups: a realist review in general practice. $\mathrm{Br} J$ Gen Pract. 2015;65(641):e813-e821.

3. Pepin R, Segal DL, Coolidge FL. Intrinsic and extrinsic barriers to mental health care among community-dwelling younger and older adults. Aging Ment Health. 2009;13(5):769-777.

4. Rowan K, McAlpine DD, Blewett LA. Access and cost barriers to mental health care, by insurance status, 1999-2010. Health Aff (Millwood). 2013;32(10):1723-1730.

5. Cunnigham PJ. Beyond parity: primary care physicians' perspectives on access to mental health care. Health Aff (Millwood). 2013;28(3):w490-w501.

6. Poushter J. Smartphone ownership and internet usage continues to climb in emerging economies. 2016. Available from: http://www.pewglobal. org/2016/02/22/smartphone-ownership-and-internet-usage-continuesto-climb-in-emerging-economies. Accessed May 9, 2017. 
7. Quintiles IMS. IMS health study: patient options expand as mobile healthcare apps address wellness and chronic disease treatment needs. 2015. Available from: http://www.imshealth.com/en/about-us/news/ ims-health-study:-patient-options-expand-as-mobile-healthcare-appsaddress-wellness-and-chronic-disease-treatment-needs. Accessed May 9, 2017

8. Anthes E. Mental health: there's an app for that. Nature. 2016;532(7597): 20-23.

9. Vöhringer PA, Barroilhet SA, Amerio A, et al. Cognitive impairment in bipolar disorder and schizophrenia: a systematic review. Front. Psychiatry. 2013;4:87.

10. Rotondi AJ, Eack SM, Hanusa BH, Spring MB, Haas GL. Critical design elements of e-health applications for users with severe mental illness: singular focus, simple architecture, prominent contents, explicit navigation, and inclusive hyperlinks. Schizophr Bull. 2015;41(2):440-448.

11. Depp CA, Mausbach B, Granholm E, et al. Mobile interventions for severe mental illness: design and preliminary data from three approaches. J Nerv Ment Dis. 2010;198(10):715-721.

12. Ben-Zeev D, Davis KE, Kaiser S, Krzsos I, Drake RE. Mobile technologies among people with serious mental illness: opportunities for future services. Adm Policy Ment Health. 2013;40(4):340-343.

13. Borzekowski DL, Leith J, Medoff DR, et al. Use of the Internet and other media for health information among clinic outpatients with serious mental illness. Psychiatr Serv. 2009;60(9):1265-1268.

14. Robotham D, Satkunanathan S, Doughty L, Wykes T. Do we still have a digital divide in mental health? A five-year survey follow-up. $J \mathrm{Med}$ Internet Res. 2016;18(11):e309.

15. Gay K, Torous J, Joseph A, Pandya A, Duckworth K. Digital technology use among individuals with schizophrenia: results of an online survey. JMIR Ment Health. 2016;3(2):e15.

16. Andrews G, Cuijpers P, Craske MG, McEvoy P, Titov N. Computer therapy for the anxiety and depressive disorders is effective, acceptable and practical health care: a meta-analysis. PLoS One. 2010;5(10):e13196.

17. Beiwinkel T, Kindermann S, Maier A, et al. Using smartphones to monitor bipolar disorder symptoms: a pilot study. JMIR Ment Health. 2016;3(1):e2.

18. Kane JM, Perlis RH, DiCarlo LA, Au-Yeung K, Duong J, Petrides G. First experience with a wireless system incorporating physiologic assessments and direct confirmation of digital tablet ingestions in ambulatory patients with schizophrenia or bipolar disorder. $J$ Clin Psychiatry. 2013;74(6): e533-e540.

19. Luxton DD, McCann RA, Bush NE, Mishkind MC, Reger GM. mHealth for mental health: integrating smartphone technology in behavioral healthcare. Prof Psychol Res Pr. 2011;42(6):505-512.

20. Price M, Yuen EK, Goetter EM, et al. mHealth: a mechanism to deliver more accessible, more effective mental health care. Clin Psychol Psychother. 2014;21(5):427-436.

21. Clarke G, Yarborough BJ. Evaluating the promise of health IT to enhance/expand the reach of mental health services. Gen Hosp Psychiatry. 2013;35(4):339-344.

22. Donker T, Petrie K, Proudfoot J, Clarke J, Birch MR, Christensen H. Smartphones for smarter delivery of mental health programs: a systematic review. J Med Internet Res. 2013;15(11):e247.

23. Huguet A, Rao S, McGrath PJ, et al. A systematic review of cognitive behavioral therapy and behavioral activation apps for depression. PLoS One. 2016;11(5):e0154248.

24. Firth J, Torous J. Smartphone apps for schizophrenia: a systematic review. JMIR Mhealth Uhealth. 2015;3(4):e102.

25. Liberati A, Altman DG, Tetzlaff J, et al. The PRISMA statement for reporting systematic reviews and meta-analyses of studies that evaluate healthcare interventions: explanation and elaboration. BMJ. 2009;339:b2700.

26. Faurholt-Jepsen M, Ritz C, Frost M, et al. Mood instability in bipolar disorder type I versus type II: continuous daily electronic self-monitoring of illness activity using smartphones. J Affect Disord. 2015;186: $342-349$.
27. Forchuk C, Reiss JP, O'Regan T, Ethridge P, Donelle L, Rudnick A. Client perceptions of the Mental Health Engagement Network: a qualitative analysis of an electronic personal health record. BMC Psychiatry. 2015;15:250.

28. Ly KH, Trüschel A, Jarl L, et al. Behavioural activation versus mindfulness-based guided self-help treatment administered through a smartphone application: a randomised controlled trial. BMJ Open. 2014;4(1):e003440.

29. Velligan D, Mintz J, Maples N, et al. A randomized trial comparing in person and electronic interventions for improving adherence to oral medications in schizophrenia. Schizophr Bull. 2013;39(5):999-1007.

30. Watts S, Mackenzie A, Thomas C, et al. CBT for depression: a pilot RCT comparing mobile phone vs. computer. BMC Psychiatry. 2013;13:49.

31. Ben-Zeev D, Brenner CJ, Begale M, Duffecy J, Mohr DC, Mueser KT. Feasibility, acceptability, and preliminary efficacy of a smartphone intervention for schizophrenia. Schizophr Bull. 2014;40(6):1244-1253.

32. Ben-Zeev D, Frounfelker R, Morris SB, Corrigan PW. Predictors of self-stigma in schizophrenia: new insights using mobile technologies. J Dual Diagn. 2012;8(4):305-314.

33. Ben-Zeev D, Kaiser SM, Brenner CJ, Begale M, Duffecy J, Mohr DC. Development and usability testing of Focus: a smartphone system for self-management of schizophrenia. Psychiatr Rehabil J. 2013;36(4):289-296.

34. Hidalgo-Mazzei D, Mateu A, Reinares M, et al. Psychoeducation in bipolar disorder with a SIMPLe smartphone application: feasibility, acceptability and satisfaction. J Affect Disord. 2016;200:58-66.

35. Osipov M, Behzadi Y, Kane JM, Petrides G, Clifford GD. Objective identification and analysis of physiological and behavioral signs of schizophrenia. J Ment Health. 2015;24(5):276-282.

36. Peters-Strickland T, Pestreich L, Hatch A, et al. Usability of a novel digital medicine system in adults with schizophrenia treated with sensor-embedded tablets of aripiprazole. Neuropsychiatr Dis Treat. 2016;12:2587-2594.

37. Tsanas A, Saunders KE, Bilderbeck AC, et al. Daily longitudinal self-monitoring of mood variability in bipolar disorder and borderline personality disorder. J Affect Disord. 2016;205:225-233.

38. Depp CA, Moore RC, Dev SI, Mausbach BT, Eyler LT, Granholm EL. The temporal course and clinical correlates of subjective impulsivity in bipolar disorder as revealed through ecological momentary assessment. J Affect Disord. 2016;193:145-150.

39. Moore RC, Fazeli PL, Patterson TL, et al. UPSA-M: feasibility and initial validity of a mobile application of the UCSD performance-based skills assessment. Schizophr Res. 2015;164(1-3):187-192.

40. Palmier-Claus JE, Ainsworth J, Machin M, et al. The feasibility and validity of ambulatory self-report of psychotic symptoms using a smartphone software application. BMC Psychiatry. 2012;12:172.

41. Ben-Zeev D, McHugo GJ, Xie H, Dobbins K, Young MA. Comparing retrospective reports to real-time/real-place mobile assessments in individuals with schizophrenia and a nonclinical comparison group. Schizophr Bull. 2012;38(3):396-404.

42. Husky M, Olié E, Guillaume S, Genty C, Swendsen J, Courtet P. Feasibility and validity of ecological momentary assessment in the investigation of suicide risk. Psychiatry Res. 2014;220(1-2):564-570.

43. Doherty G, Coyle D, Matthews M. Design and evaluation guidelines for mental health technologies. Interact Comput. 2010;22(4): 243-252.

44. Bidmon S, Terlutter R. Gender differences in searching for health information on the Internet and the virtual patient-physician relationship in Germany: exploratory results on how men and women differ and why. J Med Internet Res. 2015;17(6):e156.

45. Alkhaldi G, Hamilton FL, Lau R, Webster R, Michie S, Murray E. The effectiveness of prompts to promote engagement with digital interventions: a systematic review. J Med Internet Res. 2016;18(1):e6.

46. Palmier-Claus JE, Rogers A, Ainsworth J, et al. Integrating mobile-phone based assessment for psychosis into people's everyday lives and clinical care: a qualitative study. BMC Psychiatry. 2013;13:34. 
47. Belisario JS, Jamsek J, Huckvale K, O’Donoghue J, Morrison CP, Car J. Comparison of self-administered survey questionnaire responses collected using mobile apps versus other methods. Cochrane Database Syst Rev. 2015;(7):MR000042.

48. Sajatovic M, Velligan DI, Weiden PJ, Valenstein MA, Ogedegbe G. Measurement of psychiatric treatment adherence. J Psychosom Res. 2010;69(6):591-599.

49. Hollis C, Falconer CJ, Martin JL, et al. Annual research review: digital health interventions for children and young people with mental health problems - a systematic and meta-review. J Child Psychol Psychiatry. 2017;58(4):474-503.
50. Agarwal S, LeFevre AE, Lee J, et al. Guidelines for reporting of health interventions using mobile phones: mobile health (mHealth) evidence reporting and assessment (mERA) checklist. BMJ. 2016;352:11174.

51. Eysenbach G, CONSORT-EHEALTH Group. CONSORT-EHEALTH: improving and standardizing evaluation reports of Web-based and mobile health interventions. J Med Internet Res. 2011;13(4):e126.

52. Bakker D, Kazantzis N, Rickwood D, Rickard N. Mental health smartphone apps: review and evidence-based recommendations for future developments. JMIR Ment Health. 2016;3(1):e7.
Medical Devices: Evidence and Research

\section{Publish your work in this journal}

Medical Devices: Evidence and Research is an international, peerreviewed, open access journal that focuses on the evidence, technology, research, and expert opinion supporting the use and application of medical devices in the diagnosis, monitoring, treatment and management of clinical conditions and physiological processes. The identification of nove

\section{Dovepress}

devices and optimal use of existing devices which will lead to improved clinical outcomes and more effective patient management and safety is a key feature. The manuscript management system is completely online and includes a quick and fair peer-review system. Visit http://www. dovepress.com/testimonials.php to read real quotes from authors.

Submit your manuscript here: https://www.dovepress.com/medical-devices-evidence-and-research-journal 